\title{
Association between mean platelet volume and Microalbuminuria in Type 2 Diabetes Mellitus Patients
}

\author{
Joena $\mathbf{V}^{1}$, Prabhuswamy K.M ${ }^{2}$ \\ ${ }^{1}$ Dr.Virgin Joena M, Assistant Professor, ${ }^{2}$ Dr. Prabhuswamy K M, Assistant Professor, both authors are affiliated with \\ Department of General Medicine, Velammal Medical College \& Research Institute, Madurai, Chinna Anuppanadi, Tamil \\ Nadu 625009
}

Address for Correspondence: Dr. Virgin Joena M, Assistant Professor, Department of General Medicine, Velammal Medical College \& Research Institute, Madurai. Email:joenaxavier@gmail.com

\begin{abstract}
Background: Type $2 \mathrm{DM}$ is characterized by increased platelets activation, hence platelet functional markers like the mean platelet volume (MPV) can play a vital role in identifying subjects at high risk of developing microvascular complications. Objectives: To study the association between mean platelet volume and micro albuminuria and to analyse factors associated with MPV in patients with Type 2 diabetes mellitus. Materials \& Methods: A cross sectional study was conducted in the department of internal medicine, Velammal medical college and hospital, between June 2016 and December 2016. Subjects with DM, with age > 20 years were included. Latex Turbidimetric method was used to assess urine micro albumin. Results: A total of 269 diabetic patients with mean duration of disease of 4.84 years were included. There was a moderate, statistically significant positive correlation between HbA1 C level and Mean platelet volume ( $\mathrm{PCC}=-0.198, \mathrm{p}$ value 0.001 ). The other factors had shown no statistically significant correlation with MPV. There was a Statistically significant mild negative correlation between serum uric acid and MPV $(P C C=-0.196, p$ value 0.001$)$. The mean MPV in people with low and high Urine micro albumin was 7.716 \pm 0.876 and $7.705 \pm 0.890$ respectively, and the difference was statistically not significant. Concussions: Poor glycaemic control may lead to higher MPV in diabetic population. Very minimal and statistically non-significant difference was observed in mean MPV value between subjects with high micro albuminuria and low micro albuminuria.
\end{abstract}

Key words: Type 2 DM, Mean Platelet Volume, Micro albuminuria

\section{Introduction}

Type 2 Diabetes mellitus (DM) is a complex metabolic disorder that has shown a steep rise in its global prevalence from $4.7 \%$ in 1980 to $8.5 \%$ in 2014 where in number of people affected was 108 million and 422 million respectively [1], a serious public health problem. Additionally, nearly one-third of individuals with type $2 \mathrm{DM}$ are undiagnosed.

Also type $2 \mathrm{DM}$ is characterized by increased platelets activation and coagulation proteins and diminished fibrinolytic activity [2]. This change in platelet activity is linked to the microvascular complications associated with Type 2 DM like retinopathy, nephropathy and

Manuscript received: $8^{\text {th }}$ March 2017

Reviewed: $17^{\text {th }}$ March 2017

Author Corrected: $26^{\text {th }}$ March 2017

Accepted for Publication: $31^{\text {st }}$ March 2017 neuropathy [3,4]. Platelets have a vital role in physiological hemostasis and their optimal function is determined by markers like the mean platelet volume (MPV) and platelet size. The risk of thrombosis is high when there is increase in the platelet size and the consequent increase in MPV as the platelets are more reactive hemostatically thereby producing higher quantities of prothrombotic factor and thromboxane A2 [5]. Increased MPV seems to be associated with type 2 Diabetes mellitus [6] and also in diabetics, two prospective cohort studies have shown a positive relation between MPV and cardiovascular disease (CVD) [7] and all-cause mortality [8].

Microalbuminuria is considered to be the best predictor of development of nephropathy affecting $20-40 \%$ of 
patients with type $2 \mathrm{DM}$ [9]. It also strongly predicts the risk CVD independent from traditional (e.g., smoking, hyperlipidemia, hypertension) and non-traditional (e.g., C-reactive protein) risk factors [10,11]. Microalbuminuria also seems to be an indicator of microangiopathy in diabetics [12].

There is scarcity of literature even in India regarding the relation between mean platelet volume and microalbuminuria, hence the present study aims to assess the same in diabetic patients.

\section{Aims \& Objectives}

- To study the association between mean platelet volume and micro albuminuria in patients with Type 2 diabetes mellitus

- To assess the factors associated with mean platelet volume in patieints with Type 2 Diabetes mellitus

\section{Materials and methods}

Study design: The current study is a cross sectional study.

Study setting: The study was conducted in the department of internal medicine, Velammal medical college and hospital

Study duration: The study was conducted between June 2016 and December 2016

Study population: All the known and newly diagnosed cases of diabetes mellitus were included in the study

\section{Inclusion criteria}

1. Aged above 20 years

2. Both male \& female

\section{Exclusion criteria}

1. Elevated renal parameters and gout
Ethical issues: The study has been approved by institutional human ethics committee. After obtaining informed written consent for each participant, thorough history was obtained regarding the duration of diabetes, treatment, glycaemic control and occurrence of any complications.

$5 \mathrm{ml}$ of venous blood was drawn with aseptic precautions and all relevant parameters like Hba1c, platelet related parameters and renal parameters were assessed.

Direct Enzymatic Assay method and Latex Turbidimetric method were used respectively to assess serum uric acid and urine micro albumin.

Statistical methods: Urine micro albumin was considered as the primary outcome variable. Mean platelet volume was considered as primary explanatory variable.

Duration of diabetes mellitus, age of the patient, glycemic control as assessed by Hba1C levels, lipid profile parameters were considered as explanatory variables.

Descriptive analysis was carried out by mean and standard deviation for quantitative variables, frequency and proportion for categorical variables.

Data was also represented using appropriate diagrams like bar diagram, pie diagram and box plots.

Association between quantitative explanatory and outcome variables was assessed by calculating pearson correlation coefficient and the data was represented in a scatter diagram. $\mathrm{P}$ value $<0.05$ was considered statistically significant. IBM SPSS version 22 was used for statistical analysis [13].

\section{Observations \& Results}

Final analysis has included 269 patients. The mean age was $54.29 \pm 11.23$ years and male to female ratio was 2.84 . Majority $(60.59 \%)$ of the study subjects were known diabetics.

The mean duration of diabetes was 4.85 years. Known hypertensive constituted $29 \%$ and another $14.87 \%$ were recently diagnosed with hypertension. The mean HbA1c level in study population was $7.53 \%$. The mean values of lipid profile parameters, blood urea and serum creatinine were within normal physiological limits.

The mean serum uric acid level was $4.95 \pm 1.48$ and the mean urinine micro albumin level was $34.56 \pm 71.39$ in study population. The mean platelet volume level was $7.71 \pm 0.87$ in study population (table 1 ) 
Table-1: Descriptive analysis of socio demographic parameters in study group $(\mathrm{N}=269)$.

\begin{tabular}{|c|c|}
\hline Parameter & Summary \\
\hline Age ( mean \pm SD) & $54.297 \pm 11.23$ \\
\hline Male : Female Ratio & $2.84: 1$ \\
\hline Duration of diabetes $($ mean \pm SD) & $4.845 \pm 6.51$ \\
\hline \multicolumn{2}{|l|}{ Diabetes History } \\
\hline - Known Case & $163(60.59 \%)$ \\
\hline - Recently Diagnosed & $106(39.41 \%)$ \\
\hline \multicolumn{2}{|l|}{ Hypertension } \\
\hline - Known Case & $78(29 \%)$ \\
\hline - Recently Diagnosed & $40(14.87 \%)$ \\
\hline $\mathrm{HbA1c}$ & $7.536 \pm 1.843$ \\
\hline Blood Urea & $22.28 \pm 7.544$ \\
\hline Serum Creatinine & $0.805 \pm 0.225$ \\
\hline Uric Acid & $4.955 \pm 1.482$ \\
\hline Urine Micro albumin & $34.56 \pm 71.39$ \\
\hline Mean Platelet Volume & $7.71 \pm 0.87$ \\
\hline
\end{tabular}

Table-2: Correlation between various diabetes related parameters and Mean Platelet Volume in study group

\begin{tabular}{|c|c|c|}
\hline parameter & $\begin{array}{c}\text { Pearson Correlation Coefficient } \\
\text { (PCC) }\end{array}$ & P value \\
\hline Age & -0.048 & 0.431 \\
\hline Duration of diabetes & -0.007 & $\mathbf{0 . 0 0 1}$ \\
\hline HbA1c & 0.198 & 0.263 \\
\hline Total Cholesterol & -0.069 & 0.232 \\
\hline HDL & -0.073 & 0.382 \\
\hline LDL & -0.053 & 0.852 \\
\hline TGL & -0.011 & 0.676 \\
\hline Blood Urea & 0.026 & 0.001 \\
\hline Serum uric acid & & \\
\hline
\end{tabular}

There was a moderate, statistically significant positive correlation between HbA1 C level and Mean platelet volume in the study group ( $\mathrm{PCC}=-0.198$, $\mathrm{p}$ value 0.001 ). The other factors had shown no statistically significant correlation with Mean Platelet volume in the study group. There was a statistically significant mild negative correlation between serum uric acid and MPV (PCC $=-0.196, \mathrm{p}$ value 0.001). (Table 2) 

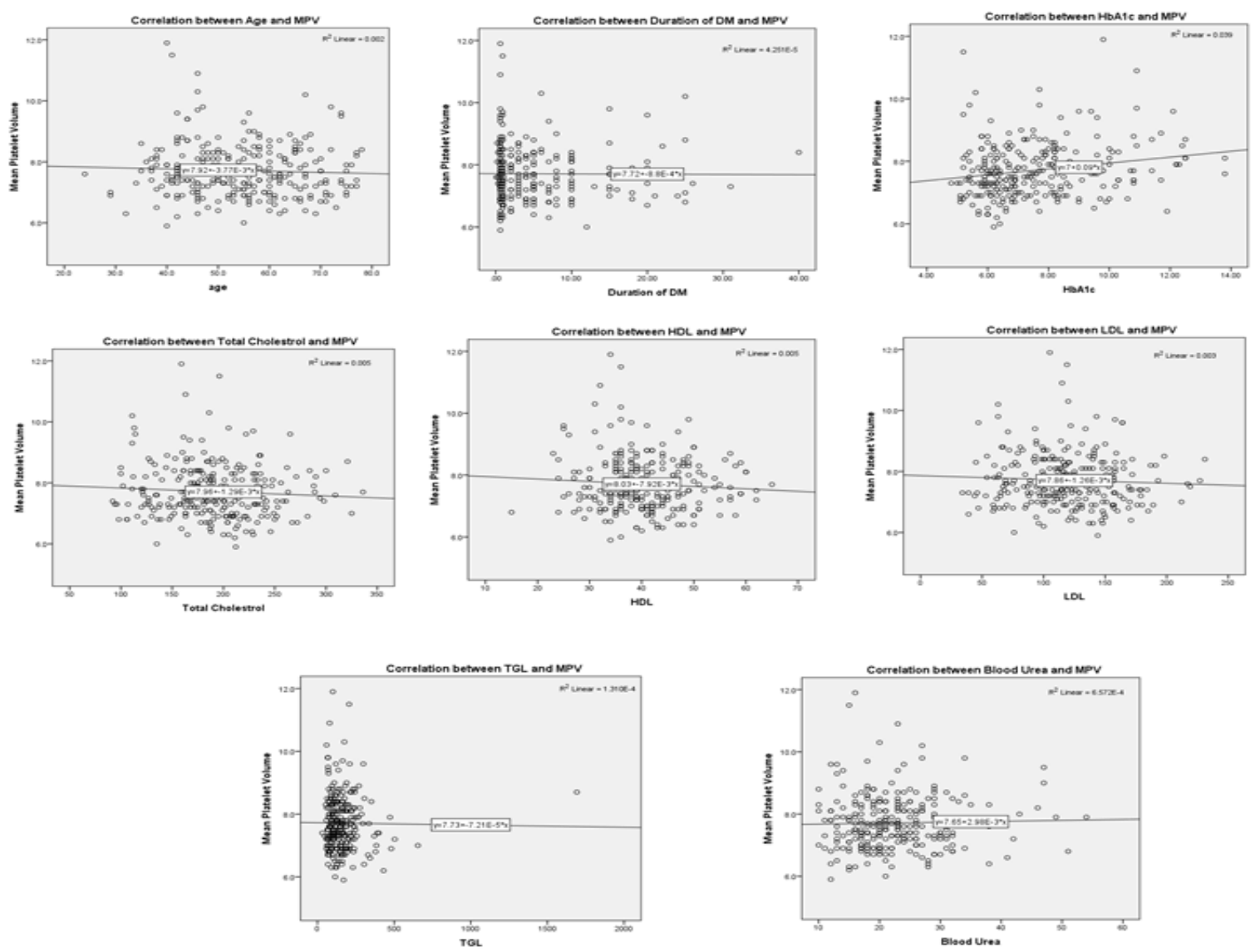

Figure-1: Correlation between various diabetes related parameters and Mean Platelet Volume

Table-3: Association between duration of diabetes and MPV in study group ( $=269)$

\begin{tabular}{|c|c|c|c|c|c|}
\hline \multirow{2}{*}{$\begin{array}{c}\text { Duration of } \\
\text { Diabetes }\end{array}$} & \multirow{2}{*}{$\begin{array}{c}\text { MPV } \\
\text { Mean } \pm \text { Std. } \\
\text { Dev }\end{array}$} & \multirow{2}{*}{ Mean difference } & \multicolumn{2}{|c|}{ 95\% Confidence Interval for Mean } & \multirow{2}{*}{$P$ value } \\
\hline & & & Lower Bound & Upper Bound & \\
\hline$<5$ & $7.722 \pm 0.882$ & & & & \\
\hline 6 to 10 & $7.663 \pm 0.831$ & 0.059 & -0.31 & 0.435 & 1.00 \\
\hline$>11$ & $7.718 \pm 0.929$ & 0.003 & -0.40 & 0.408 & 1.00 \\
\hline
\end{tabular}

The mean MPV in people with duration of diabetes < 5 years was $7.722 \pm 0.882,6$ to 10 years was $7.663 \pm 0.831$ and > 11 years was $7.718 \pm 0.929$ in study population. There was no statistically significant association between duration of diabetes mellitus and mean platelet volume in study group. (Table 3)

Table-4: Association between Urine micro albumin and Mean Platelet Volume (N=269)

\begin{tabular}{|c|c|c|c|c|c|}
\hline \multirow{2}{*}{ Urine Micro albumin } & \multirow{2}{*}{$\begin{array}{c}\text { Mean Platelet Volume } \\
\text { Mean } \pm \text { STD }\end{array}$} & \multirow{2}{*}{$\begin{array}{c}\text { Mean } \\
\text { difference }\end{array}$} & \multicolumn{2}{|c|}{$95 \% \mathrm{CI}$} & \multirow{2}{*}{$P$ value } \\
\hline & & & Lower & Upper & \\
\hline Low ( up to 29.99) & $7.716 \pm 0.876$ & \multirow{2}{*}{0.01} & \multirow{2}{*}{-0.22990} & \multirow{2}{*}{0.25163} & \multirow{2}{*}{.914} \\
\hline High (30 and above) & $7.705 \pm 0.890$ & & & & \\
\hline
\end{tabular}

The mean MPV in people with low Urine micro albumin was $7.716 \pm 0.876$ and in people with high urine micro albumin was $7.705 \pm 0.890$. There was no statistically significant association between urine micro albumin and mean platelet volume in study group. (Table 4). 


\section{Discussion}

The vascular complications in DM patients pose higher risk of morbidity and mortality. Patients with type 2 DM usually develop early interruption of endothelial functions, hyper-activation of platelets and progressive atherosclerosis [14]. This is one of the suggested mechanisms of atherosclerosis among diabetics. Increased platelet reactivity leads to enhanced platelet volume [15] due to altered platelet size and density. MPV refers to the average of the size of the platelets in the blood [16].

The MPV and platelet counts are not only indicators of thrombotic potential, but also risk factors for microvascular complications in diabetics [17-19]. Such platelets synthesize more thromboxane $\mathrm{A} 2$, are able to aggregate better, and are able to secrete more serotonin and $\beta$ - thromboglobulin than regular platelets $[20,21]$. The most recent systematic review concluded that the annual incidence of microalbuminuria is higher among patients with type $2 \mathrm{DM}(\sim 8 \%)$ than those with type 1 $(\sim 2-3 \%)$ [22].

The mean age of the study participants was 54.29 \pm 11.23 years and the mean duration of diabetes was $4.85 \pm 6.51$ years This was in contrast to study done by Papanas $\mathrm{N}$ et al., [23] who reported their mean age of the diabetics as $67.4 \pm 9.5$ years and a mean diabetes duration of $14.5 \pm 5.7$ years. However, Hasan $\mathrm{Z}$ et al., [24] found their patients diabetes duration as $4 \pm 5.6$ years which was similar to our study. Among the total, $60.59 \%$ were known cases of diabetes and remaining $39.41 \%$ were diagnosed recently $(<1$ year $)$.

Prolonged hyperglycemia leads to a series of interconnected changes leading to endothelial dysfunction and vascular injuries resulting in further complications in diabetics [25]. Some of the proposed mechanisms include; synthesis of advanced glycation end products, protein kinase $\mathrm{C}$ activation and disruption of polyol pathways [24].

There was a moderate, statistically significant positive correlation between HbA1 C level and Mean platelet volume in the study group $(\mathrm{r}=-0.198$, $\mathrm{p}$ value 0.001$)$. In comparison Hasan Z et al., [24] reported a slightly lesser and non significant correlation $(r=0.115)$. Contrastingly the studies by Hasan $\mathrm{Z}$ et al., [24] and Yenigün EC et al., [26] reported no association between MPV and HbA1 C.
There was no statistically significant association between duration of diabetes mellitus and mean platelet volume in study group. This finding is in concurrence with that of Hasan Z et al., [24]. In their study, Kodiatte et al., found a significant correlation between MPV and duration of DM [27]. However, Zuberi et al., [28] reported that patients with longer duration of DM had high prevalence of microvascular complications. Also there was no statistically significant association between urine micro albumin and mean platelet volume in study group.

To minimize the impact of the complications in DM patients as they increase day by day, an approach to modify the risk factors is necessary.

Regarding the limitations of our study, the lack of controls and a relatively smaller sample might lessen the significance of the findings observed in the study population. Also assessing the patietns from a single institution might limit the generalizability of the study findings.

\section{Conclusions}

1. The mean MPV had shown a significant positive correlation with HbA1C levels in study population. Hence poor glycaemic control may lead to higher MPV in diabetic population

2. Duration of diabetes mellitus had shown no statistically significant association with MPV in the study population.

3. Very minimal and statistically non-significant difference was observed in mean MPV value between subjects with high microalbuminuria and low micro albuminuria.

Recommendations: Further large scale studies on the subject with higher sample size may provide us better understanding of role of MPV as an early marker of subsequent development of micro and macro vascular complications of diabetes.

\section{Funding: Nil, Conflict of interest: None Permission of IRB: Yes}

\section{References}

1. Organisation. WH. Global report on diabetes. WHO, Geneva. 2016. 
2. Carr ME. Diabetes mellitus: a hypercoagulable state. J Diabetes Complications. 2001 Jan-Feb;15(1):44-54.

3. Mandal S, Sarode R, Dash S, Dash RJ. Hyperaggregation of platelets detected by whole blood platelet aggregometry in newly diagnosed noninsulindependent diabetes mellitus. Am J Clin Pathol. 1993 Aug;100(2):103-7.

4. MJ. F. Microvascular and macro- vascular complications of diabetes. Clin Diabetes. 2011;29: 116-22.

5. Vizioli L, Muscari S, Muscari A. The relationship of mean platelet volume with the risk and prognosis of cardiovascular diseases. Int J Clin Pract. 2009 Oct; 63 (10): 1509-15. doi: 10. 1111/j. 1742-1241. 2009. 02070.x.

6. Papanas N, Symeonidis G, Maltezos E, Mavridis G, Karavageli E, Vosnakidis T, Lakasas G. Mean platelet volume in patients with type 2 diabetes mellitus. Platelets. 2004 Dec;15(8):475-8.

7. Han JY CD, Choi SW, Kim BB, Ki YJ, Chung JW, Koh YY, Chang KS, Hong SP. . Stroke or coronary artery disease prediction from mean platelet volume in patients with type 2 diabetes mellitus. Platelets. 2013; 24(5):401-6.

8. Lekston A, Hudzik B, Hawranek M, Szkodzinski J, Gorol J, Wilczek K, Gasior M, Polonski L. Prognostic significance of mean platelet volume in diabetic patients with ST-elevation myocardial infarction. J Diabetes Complications. 2014 Sep-Oct;28(5):652-7. doi: 10.1016 /j. jdiacomp.2014.05.002. Epub 2014 May 16.

9. American Diabetes Association. Standards of medical care in diabetes--2010. Diabetes Care. 2010 Jan; 33 Suppl 1:S11-61. doi: 10.2337/dc10-S011.

10. Garg JP, Bakris GL. Microalbuminuria: marker of vascular dysfunction, risk factor for cardiovascular disease. Vasc Med. 2002 Feb;7(1):35-43.

11. Stehouwer CD GM, Twisk JW, Knudsen E, Emeis JJ, Parving HH. Increased urinary albumin, endothelial dysfunc- tion and chronic low grade inflammation in type 2 diabetes: Progressive, interrelated and independently associated with risk of death. Diabetes. 2002;51:1157-165.
12. Klausen K B-JK, Feldt-Rasmussen B, Jensen G, Clausen P, Scharling H, Appleyard M, Jensen JS. V. Very low levels of microalbuminuria are associated with increased risk of coronary heart disease and death independently of renal function, hypertension, and diabetes. Circulation 2004;110:32-5.

13. Machines IB. IBM SPSS Statistics for Windows, Version 22.0. IBM Corp Armonk, NY; 2013.

14. Klausen K B-JK, Feldt-Rasmussen B, Jensen G, Clausen P, Scharling H, Appleyard M, Jensen JS Very low levels of microalbuminuria are associated with increased risk of coronary heart disease and death independently of renal function, hypertension, and diabetes. Circulation. 2004;110:32-5.

15. Bessman JD. The relation of megakaryocyte ploidy to platelet volume. Am J Hematol. 1984 Feb;16(2): 161-70.

16. van der Loo B, Martin JF. Megakaryocytes and platelets in vascular disease. Baillieres Clin Haematol. 1997 Feb;10(1):109-23.

17. Hekimsoy Z, Payzin B, Ornek T, Kandoğan G. Mean platelet volume in Type 2 diabetic patients. J Diabetes Complications. 2004 May-Jun;18(3):173-6.

18. Zuberi BF, Akhtar N, Afsar S. Comparison of mean platelet volume in patients with diabetes mellitus, impaired fasting glucose and non-diabetic subjects. Singapore Med J. 2008 Feb;49(2):114-6.

19. Bae SH, Lee J, Roh KH, Kim J. Platelet activation in patients with diabetic retinopathy. Korean $\mathbf{J}$ Ophthalmol. 2003 Dec;17(2):140-4.

20. Colwell JA, Nesto RW. The platelet in diabetes: focus on prevention of ischemic events. Diabetes Care. 2003 Jul; 26(7):2181-8.

21. Ates O KI, Bilen H, Keles M, Koçer I, Kulaçoglu DN, et al. Association of Mean Platelet Volume With The Degree of Retinopathy in Patients with Diabetes Mellitus. Eur J Gen Med. 2009;6(2):99-102.

22. Koye DN, Shaw JE, Reid CM, Atkins RC, Reutens AT, Magliano DJ. Incidence of chronic kidney disease among people with diabetes: a systematic review of 


\section{Original Research Article}

observational studies. Diabet Med. 2017 Feb 6. doi: 10. 1111/dme.13324. [Epub ahead of print]

23. Papanas N, Symeonidis G, Maltezos E, Mavridis G, Karavageli E, Vosnakidis T, Lakasas G. Mean platelet volume in patients with type 2 diabetes mellitus. Platelets. 2004 Dec; 15(8):475-8.

24. Hasan Z HS, Uday I, Jayakumar MN, Anantharajaiah PH. Assessment of Mean Platelet Volume in Type 2 Diabetes Mellitus and Prediabetes. NJLM. 2016;5(3):PO54-PO7.

25. Bae SH, Lee J, Roh KH, Kim J. Platelet activation in patients with diabetic retinopathy. Korean $J$ Ophthalmol. 2003 Dec;17(2):140-4.
26. Yenigün EC OG, Pirpir A, Hondur A, Yıldırım S. Increased mean platelet volume in type 2 diabetes mellitus. Dicle Tip Dergisi. 2014; 41 (1): $17-22$.

27. Kodiatte TA, Manikyam UK, Rao SB, Jagadish TM, Reddy M, Lingaiah HK, Lakshmaiah V. Mean platelet volume in Type 2 diabetes mellitus. J Lab Physicians. 2012 Jan; 4(1):5-9. doi: 10. 4103 /0974-2727. 98662.

28. Zuberi BF AN, Afsar S. Comparision of mean platelet volume in patients with diabetes mellitus, impaired glucose and non diabetic subjects. Singapore Med J. 2008;49:114-16.

\section{How to cite this article?}

Joena V, Prabhuswamy K.M. Association between mean platelet volume and Microalbuminuria in Type 2 Diabetes Mellitus Patients. Int J Med Res Rev 2017;5(03):331-337 doi:10.17511/ijmrr. 2017.i03.19. 